\title{
Arborização urbana: Percepção ambiental dos moradores dos bairros Bom Pastor e Centro da cidade de Ubá/MG
}

\author{
Urban Forestry: environmental perceptions of residents os neighbourhoods Bom Pastor And Centro city Uba/MG \\ Bruna Vieira Pizziolo', Renata Tostes², Kelly Silva², Viviane Modesto Arruda² \\ ' Departamento de Ciências Biológicas, Universidade do Estado de Minas Gerais, Belo Horizonte, Brasil. \\ 2 Área de Botânica, Departamento de Ciências Biológicas, Universidade do Estado de Minas Gerais, Belo Horizonte, Brasil. \\ ${ }^{3}$ Educação, Departamento de Humanas, Universidade do Estado de Minas Gerais, Belo Horizonte, Brasil..
}

\section{Resumo}

A percepção ambiental é responsável pelo entendimento do homem das inter-relações do indivíduo com o meio ambiente. Sem um nível satisfatório de percepção ambiental, os indivíduos tendem a dificultar a aplicação de projetos ambientais, tornando muitos deles inviáveis. Este trabalho tem como objetivo analisar a percepção ambiental, dos moradores da cidade de Ubá, ,em relação à arborização urbana, com vistas à implantação de um projeto de educação ambiental na cidade. Para isso aplicou-se um questionário aos moradores dos dois bairros da região central do município. Os resultados demonstram que a população reconhece os benefícios da arborização no controle do microclima urbano, contudo não possuem um conhecimento adequado sobre todos os benefícios da arborização urbana, a quem cabe à sua manutenção. Estes dados reforçam a necessidade de um planejamento da arborização do município, com implantação de um projeto de educação ambiental, buscando conscientizar a população de sua importância.

Palavras-chave: Arborização, Percepção, Meio ambiente.

\begin{abstract}
Environmental awareness is responsible for understanding the man of the interrelationships of the individual with the environment. Without a satisfactory level of environmental awareness, individuals tend to hamper implementation of environmental projects, making many of them unviable. This work aims to analyze the environmental perception of residents in Uba regarding urban forestry, with a view to implementing an environmental education project in the city . For this we applied a questionnaire to residents of two neighborhoods in the central city. The results show that people recognize the benefits of trees in urban microclimate control, but does not have a proper knowledge about all the benefits of urban forestry, and is responsible for its maintenance. These data reinforce the need for planning afforestation of the municipality with the implementation of an environmental education project, seeking to raise awareness of its importance.
\end{abstract}

Keywords: A afforestation, Perception, Environment. 


\section{INTRODUÇÃO}

Percepção ambiental pode ser definida como uma tomada de consciência, por parte dos indivíduos, sobre o meio em que se encontram inseridos, aprendendo a respeitar, proteger e cuidar (CARVALHO, 2010). O estudo da percepção ambiental possui grande importância para a compreensão das inter-relações entre o homem e o ambiente. Segundo Del Rio; Oliveira (1999), para que se tenha um melhor planejamento e uma melhor estrutura no crescimento das cidades, é necessário que seja feito um planejamento e uma compreensão do ambiente urbano, e estudos que priorizem a percepção da população em relação ao ambiente.

De acordo com Instituto Brasileiro de Geografia e Estatística (IBGE, 2010), a maior parte da população brasileira vive em cidades, $84,35 \%$, sendo que no Estado de Minas Gerais esse índice é de $85,29 \%$. Este acelerado e inadequado processo de crescimento, que as cidades do interior do Brasil enfrentaram nas últimas décadas, provocou a degeneração do meio ambiente urbano, que ocasionou condições nada ideais para a sobrevivência humana, levando a uma insatisfação da população (Oliveira, et al., 2013).

As árvores constituem parte viva de qualquer cidade, proporcionando inúmeros benefícios à população. Dentre alguns dos grandes benefícios proporcionados pela arborização urbana, segundo os autores, está o amortecimento de ruídos e a redução do impacto da água da chuva (GUZZO, 2006; SILVA, 2005; MASCARÓ, 1996; MELLO FILHO, 1985), a conservação da biodiversidade, a manutenção de banco genético e o abrigo e a diversificação de fontes de alimentação para a fauna (CPFL, 2008).

O aumento da diversidade de espécies dentro das cidades auxilia na ampliação do equilíbrio das cadeias alimentares e na diminuição de pragas e doenças, como consequência do equilíbrio ecológico, bem como a redução da velocidade do vento e a retenção de umidade, por meio da sombra produzida por elas (GUZZO, 2006; GUZZO, 1999; MILANO, 1988).

Entretanto, se a arborização urbana não for feita de forma correta e planejada, pode gerar muitos problemas, tais como: interferência na rede elétrica, destruição da pavimentação e de sistemas hidráulicos, entupimento de calhas, abalo na estrutura das casas, entre outros. Devido a esses problemas, torna-se comum as árvores serem podadas drasticamente, ficando mais suscetíveis a problemas fitossanitários, como a presença de broca, cupins, patógenos, troncos ocos e podres, galhos secos e lascados (MAREK, 2008).

Segundo Azambuja; Bianchini (2003), quando a arborização não é bem planejada, isto é, quando a espécie é plantada sem nenhuma análise prévia, faz com que certos elementos da vegetação ocasionem problemas diversos, que podem levar a população à exclusão do elemento arbóreo "causador de problemas", por esse motivo deve-se instruir o cidadão que árvores existem para o bem estar e não para prejudica-lo.

Silva et al., (2012) realizou um diagnóstico da arborização urbana no município de Ubá, localizado na Zona da Mata Mineira, e constatou que o município possui uma arborização urbana mal planejada, apresentando diversos problemas técnicos de execução, que contribuem para piorar a qualidade de vida da cidade. Embora esteja presente tanto na Lei Orgânica municipal quanto no Plano diretor, o direito do cidadão "a um ambiente ecologicamente equilibrado", a cidade ainda não possui uma política voltada para a arborização.

Devido a este problema, o presente trabalho tem como objetivo analisar a percepção ambiental dos moradores de dois bairros da cidade de Ubá, quanto à arborização urbana, para subsidiar a administração municipal no planejamento e gestão da arborização urbana, bem como para implantação de um programa de educação ambiental, na cidade, voltado para este tema.

\section{MATERIAL E MÉTODOS}

O presente estudo foi realizado em dois bairros pertencentes ao município de Ubá, bairro Bom Pastor e Bairro Centro (Figura 1 e 2). A escolha destes dois bairros deu-se em função dos bairros terem seu índice de arborização bem diferenciado, sendo o Bairro centro o de maior índice de arborização do município e o Bairro Bom Pastor o de menor índice, conforme demostrado no trabalho, desenvolvido por Silva et al., (2012), sobre o diagnóstico da arborização urbana de 14 bairros na região central da cidade. 
Para a coleta de dados foi utilizado um questionário semiestruturado com dezesseis perguntas sobre a arborização, sendo onze perguntas objetivas e cinco perguntas dissertativas. Este questionário era utilizado como roteiro para as entrevistas com os moradores, sendo estas gravadas com gravador de áudio, para uma melhor análise dos resultados.

Os questionários foram respondidos de acordo com a disposição, por parte dos moradores, em participar da pesquisa, de forma aleatória, e nele foram abordadas questões a respeito dos índices de arborização dos bairros, os problemas e os benefícios causados pela arborização, a colaboração dos moradores na arborização. Além de questões acerca da arborização, foram levantados, também, dados demográficos, como em relação ao gênero, à idade e à escolaridade.

Foram aplicados questionários nos bairros, preferencialmente nas casas, sendo que cada casa respondeu apenas um questionário. O critério de escolha dos participantes foi, essencialmente, ser morador de uma das áreas investigadas, isto é, ser um dos responsáveis pela moradia e ter idade superior a 18 anos. Este critério de idade foi estabelecido por entender que os mesmos já são capazes de tomar decisões em relação à retirada ou à implantação da arborização.

Esses questionários foram analisados fazendo um levantamento sobre a percepção ambiental dos moradores de cada bairro selecionado, comparando com as condições arbóreas dos bairros em questão, realizando-se uma análise estatística descritiva dos dados.

\section{RESULTADOS E DISCUSSÃO}

Foram aplicados, no total, 140 questionários, sendo 70 questionários no Bairro Bom Pastor e 70 questionários no bairro Centro. No bairro Bom Pastor, a maioria dos entrevistados, $67 \%$, foram do sexo feminino, já no bairro centro, $59 \%$ dos entrevistados foram do sexo masculino. Esta diferença entre a porcentagem de gênero entre os bairros deu-se em função das entrevistas terem sido realizadas em horários e dias diferentes.

Todos os entrevistados responderam sozinhos o questionário, sem pedir ajuda a nenhum outro membro da família. Segundo Quadros e Frei (2009), "Percepção é, por definição, o ato, o efeito ou a faculdade de perceber, adquirir conhecimento a partir de algo por meio dos sentidos, compreender, ouvir" e os entrevistados demonstraram que possuem essa faculdade, já que não transferiram a outra pessoa a decisão sobre a resposta.

Em relação à faixa etária, o percentual de entrevistados com idade entre 21 e 40 anos foi maior nos dois bairros. No bairro Bom Pastor, esse percentual foi de 51\%. Com idade de 18 a 20 anos, o percentual foi de $19 \%$, e $30 \%$ tinham idade superior a 41 anos. No centro da cidade, $43 \%$ dos entrevistados tinham de 21 a 40 anos, $21 \%$ tinham até 20 anos, e $36 \%$ acima de 41 anos.

Quanto ao nível de escolaridade da população entrevistada, foi bastante variável. De acordo com os dados obtidos no bairro Bom Pastor, $8 \%$ dos entrevistados possuía ensino superior completo, aproximadamente $26 \%$ ensino médio completo, $46 \%$ possuíam ensino fundamental completo, $17 \%$ ensino fundamental incompleto e $3 \%$ não eram alfabetizados.

No centro da cidade, $13 \%$ das pessoas entrevistadas possuíam o ensino superior completo, $25 \%$ ensino médio completo, $53 \%$ possuíam ensino fundamental completo, $9 \%$ ensino fundamental incompleto e não houve nenhuma pessoa não alfabetizada que respondesse à pesquisa.

Quando questionados sobre como classificam o bairro quanto ao percentual de arborização, no bairro Bom Pastor, nenhum entrevistado considerou o bairro muito arborizado. No bairro centro, $97 \%$ dos entrevistados consideraram o bairro muito arborizado. No bairro Bom Pastor, $40 \%$ classificam o bairro como razoavelmente arborizado e $50 \%$ como pouco arborizado e $10 \%$ como não possui nenhuma arborização. No Centro, classificaram o bairro como muito arborizado ( $97 \%$ dos entrevistados), $1 \%$ como razoavelmente arborizado, $1 \%$ como pouco arborizado, e $1 \%$ como não possui nenhuma arborização (Figura 1).

No levantamento realizado por Silva et al., (2012), os bairros em questão apresentaram índices de arborização bastante diferentes, sendo que o Bairro Centro possui os maiores índices, em contrapartida, o bairro Bom Pastor apresentou o menor índice de arborização. Este dado demonstra que a população dos dois bairros consegue perceber se seus bairros são muito arborizados ou não.

Quando questionados sobre os principais benefícios trazidos pela arborização urbana, $30 \%$ dos 


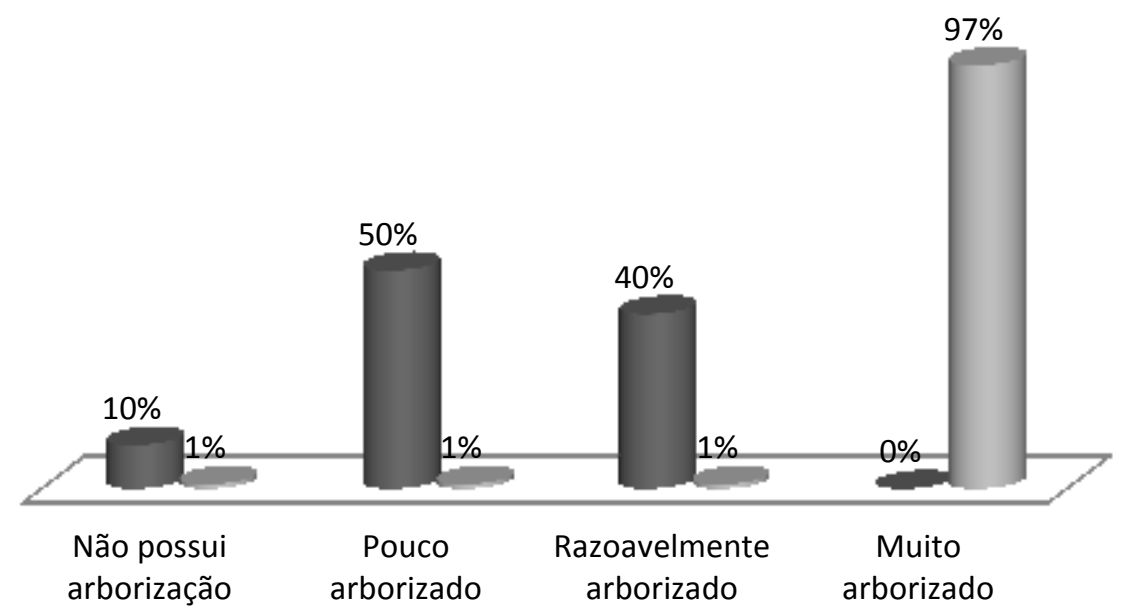

Figura1. Percentual de arborização dos Bairros Bom Pastor e Centro

entrevistados do bairro Bom Pastor considerou que a principal importância seria a redução do calor e $66 \%$ considerou a presença de sombra, ou seja, $96 \%$ dos moradores citou fatores de manutenção do microclima como principal função, conforme visto na (Figura 2). Os demais $4 \%$ dos entrevistados não perceberam nenhuma importância.

No bairro centro, os números não são muito diferentes, $99 \%$ dos entrevistados considerou a presença de sombra a principal importância da arborização. A presença de árvores é fundamental para amenizar os microclimas mais quentes, ajudando no aumento da umidade do ar, além de diversos outros fatores (MIRANDA; CARVALHO, 2009).

Gomes e Amorim (2003) afirmam que algumas espécies utilizadas na arborização urbana reduzem os efeitos da radiação solar e oferecem conforto térmico ao ambiente. A sombra e a redução do calor são vantagens predominantes em grande parte dos estudos que avaliam a percepção dos moradores quanto à arborização urbana no Brasil (Malavasi; Malavasi, 2001; Roppa et al., 2007; Araújo et al., 2010).

Esse resultado pode ser explicado por que os dois bairros estudados são urbanizados, localizando-se geograficamente na região central da cidade, com isso apresentam muitos prédios, o que torna o microclima da localidade ainda mais quente sem a presença de árvores, o que leva ao fenômeno conhecido como ilha de calor, fenômeno "[...] caracterizado pelo incremento da temperatura nas regiões centrais da cidade em relação às suas áreas circunvizinhas" (TEJAS et al., 2011).

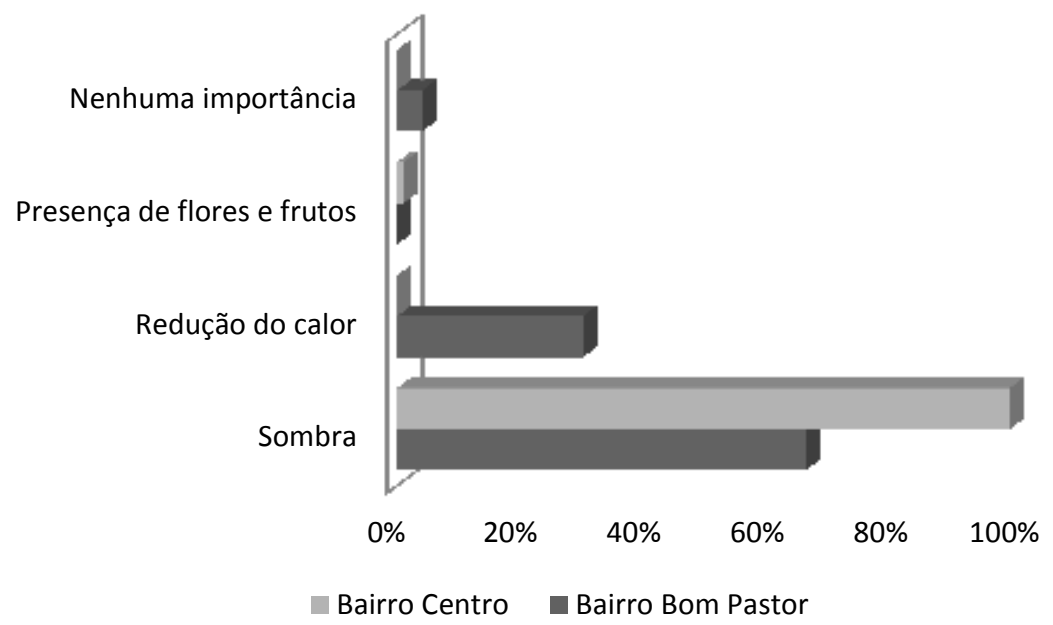

Figura 2. Benefícios da arborização segundo os entrevistados dos Bairros Boa Pastor e Centro 
Investigando sobre a percepção dos moradores, sobre quem deve realizar a manutenção e plantio das árvores, $57 \%$ das pessoas entrevistadas no bairro Bom Pastor acredita que a manutenção e o plantio devem ser realizados pela prefeitura. Dos entrevistados, 3\% acredita que são outros órgãos ligados ao meio ambiente, $3 \%$ opinaram que não precisa de manutenção, e $37 \%$ acreditam que seja dos próprios moradores.

No bairro centro não ocorreu resposta que seria de outros órgãos, e os pesquisados se dividiram em $89 \%$ responsabilidade da prefeitura, $11 \%$ que é dos próprios moradores. Segundo CPFL Energia (2008), "Da interpretação dos artigos n. 30, 182 e 183 da Constituição da República Federativa do Brasil, em vigor, e dos artigos n. 98 e 99 do Código Civil, torna-se clara a conclusão de que é das prefeituras municipais a responsabilidade pelo manejo das árvores urbanas".

Uma questão que deve ser levantada é que $48 \%$ do total de entrevistado nos dois bairros atribuem a manutenção da arborização aos próprios moradores. Segundo Silva et al. (2008), grande parte das prefeituras não possui projetos nem de plantio de árvores, nem de manutenção, muitas vezes o plantio e a própria manutenção, como a poda, são realizados por moradores, que não possuem o devido conhecimento técnico, o que leva a uma arborização irregular, que acaba por não desempenhar seu papel, seja biológico, seja estético.

$\mathrm{Na}$ questão que avalia a opinião dos moradores, sobre a arborização existente na localidade estudada ser adequada, pode-se ver que essa adequação na percepção dos mesmos está diretamente ligada à quantidade de árvores, e se essas produzem sombra. Não levam em conta em suas percepções se a espécie é adequada, se causa algum dano às ruas ou algum inconveniente a população.

No bairro Bom Pastor, 90\% considera que o bairro não possui arborização adequada, pois em sua concepção, tem poucas árvores e pouca sombra, e 10\% considera a quantidade de árvore e sombra adequada. No Centro, $6 \%$ dos entrevistados classificam inadequada a arborização do bairro, justificando possuir poucas árvores, outros $94 \%$ classificam como adequada a arborização urbana do bairro por possuir várias árvores, fazendo sombra e reduzindo o calor.

Nota-se que apercepção ambiental dos moradores ainda é limitada à sensação térmica. A cidade de Ubá, como abordado em Silva et al., (2012), apresenta temperaturas médias de $18,2^{\circ} \mathrm{C}$ e $31^{\circ} \mathrm{C}$ e é uma das cidades mais quentes da Zona da Mata, o que influencia na associação à sombra produzida pela copa das árvores.

Quando questionados sobre o que entendem por arborização, no bairro Bom Pastor, as respostas foram variadas, como "uma quantidade razoável de árvores no bairro", "melhoramento do clima através do plantio de árvores", " muitas árvores nas vias públicas". Não se leva em conta pelas respostas, praças e nem árvores dos quintais, por exemplo, o que mostra que a percepção dos mesmos se limita às arvores plantadas nas calçadas. No bairro centro, a maioria respondeu que entende por arborização urbana "árvores nas vias públicas", "árvores nos bairros fazendo sombra e melhorando o clima".

Quanto ao questionamento sobre as consequências negativas da arborização, no Bom Pastor nota-se que o que os moradores mais percebem são danos às casas e as calçadas, e sujeira dos pássaros. No centro, os itens que mais se evidenciaram foram danos às calçadas, às casas, danos à fiação da rede elétrica e sujeira por causa dos pássaros. Esses danos, causados e percebidos pela população, demonstram conformidade com vários dos autores pesquisados: a falta de planejamento da arborização e a escolha de espécies inadequadas geram esse tipo de problema.

Estes problemas apontados são devido ao uso de espécies inadequadas, "Algumas espécies de árvores, geralmente de grande porte, possuem raízes superficiais de dimensões impróprias às vias públicas, podendo causar danos em ruas e calçadas" (CPFL, 2008).

Segundo Barcelos et al., (2012), deve-se levar em conta a escolha da espécie de acordo com sua copa: "O formato e a dimensão da copa devem ser compatíveis com o espaço físico tridimensional disponível, permitindo o livre trânsito de veículos e pedestres, evitando danos às fachadas e conflito com a sinalização, iluminação e placas indicativas".

Sobre danos à rede elétrica, CPFL (2008) trata que "a altura e o diâmetro plenos de uma árvore, quando adulta, devem ser compatíveis com os espaços a elas destinados, evitando-se, desta forma, riscos de danos à rede elétrica [...]" e Barcelos et al., (2012) aborda que, em casos de espécies que não atendam essas características, devem ser substituídas por outras de porte e copa adequados.

No questionamento quanto à colaboração do morador entrevistado em relação a arborização das vias públicas nas localidades pesquisadas, no bairro Bom Pastor, a maior parte evidenciou que 
colabora com a manutenção somente não danificando, alguns citaram como colaboração a poda e o controle de formigas. No bairro Centro, a maior parte dos entrevistados responderam que colaboram não danificando a arborização presente nas vias públicas.

Em estudo aos diversos autores, dentre eles Prefeitura Municipal de Piracicaba (2007), Prefeitura de São Paulo (2005) e Rio Grande Energia (2000), é possível ver que, na verdade, a maior contribuição da população deve ser realmente de não danificar, uma vez que, conforme CPFL (2008), abordado anteriormente, a manutenção e o plantio em via pública devem ser feitos pela prefeitura, por profissionais qualificados para tal, evitando danos desnecessários às espécies, podas realizadas de forma errônea e, até mesmo, acidentes.

O morador pode realizar plantio em quintais, a fim de melhorar as condições do local, que deveria ser mais incentivado por parte da prefeitura e de outros órgãos responsáveis na distribuição e na informação quanto às espécies próprias.

Quando questionados quanto ao conhecimento da existência de alguma lei que proíbe o corte de árvores por moradores, no bairro Bom Pastor, 63\% dos entrevistados admite ter conhecimento e $37 \%$ dizem não ter conhecimento sobre essa lei. No Centro, $100 \%$ dos moradores admitem ter conhecimento sobre essa lei.

Uma evidência de que há falta de conscientização por parte da população é que muitos dos que conhecem a lei, no bairro Bom Pastor, admitem que realizam podas ou cortes mesmo assim, justificando o ato pela demora ou pela burocracia da prefeitura. No centro da cidade, talvez devido à diferença de escolaridade, maior acesso aos órgãos públicos ou outro fator de conscientização da importância de realizar os procedimentos com embasamento técnico, os moradores entrevistados dizem cumprir a lei, realizando a poda e o corte por meio de solicitação aos órgãos responsáveis.

No bairro Bom Pastor e no Centro, 36\% dos entrevistados dizem não saber o nome da árvore que existe em frente a sua casa e $64 \%$ sabem. Esse índice retoma, novamente, a questão de conscientização ambiental. A população desconhece o nome da espécie e, consequentemente, não sabe nenhuma informação que diga se é ou não adequada para o plantio em vias públicas.

No bairro Bom Pastor, $16 \%$ dos entrevistados disse possuir árvore no quintal de sua casa e $84 \%$ disse não possuir nenhuma espécie arbórea, $80 \%$ disse ter desejo de possuir árvores no quintal e $20 \%$ não gostaria, justificando a ocupação excessiva de espaço, por sujar com suas folhas e pela manutenção necessária.

No centro, somente $3 \%$ dos entrevistados disseram ter alguma espécie arbórea plantada, enquanto $97 \%$ disseram não as ter. Sobre o desejo de possuir um exemplar arbóreo em seu quintal, 29\% disseram que gostariam e $71 \%$ disseram que não, pelos mesmos motivos justificados pelos moradores do bairro Bom Pastor: falta de espaço físico, uma vez que muitos moram em apartamentos ou pequenas casas, com pouca área livre.

\section{CONCLUSÃO}

- Verificou-se que a população dos dois bairros não possui conhecimento sobre todos os benefícios que a arborização pode trazer para a qualidade de vida no perímetro urbano, só conseguem reconhecer a formação de sombra e a redução do calor.

- Boa parte dos entrevistados, principalmente no Bairro Bom Pastor, faz intervenções na arborização urbana, principalmente através de podas.

- Os principais problemas relatados pelos entrevistados, em relação à arborização, foram danos a casas ou passeios e sujeiras por pássaros, sendo consequência da utilização de espécies inadequadas.

- A distribuição de panfletos, contendo informações básicas sobre a arborização urbana, pode ser uma iniciativa preciosa e uma ferramenta importante para a reestruturação da arborização de muitas cidades. 


\section{REFERÊNCIAS}

AZAMBUJA, Carina Hermínia de, BIANCHINI, Joice Maria Feijó. Importância da arborização na cidade do Rio Grande. In. ENCONTRO ESTADUAL DE GEOGRAFIA, XXIII, 2003, Porto Alegre. Anais. Porto Alegre: AGB - PA, 2004. p. 381-388.

ARAÚJO, J. De L. O.; ARAÚJO, A. C. de; ARAÚJO, A. C de. Percepção ambiental dos residentes do bairro presidente médici em Campina Grande-PB, no tocante à arborização local. Revista da Sociedade Brasileira de Arborização Urbana, v.5, n.2, p.67-81, 2010.

BARCELOS, A. et al. Manual para elaboração do plano municipal de arborização urbana. Paraná, 2012.

CARVALHO, J.B. Percepção e relações ambientais dos moradores da comunidade agrícola Palestina no município de Axixa - TO. 1a Jornada de iniciação científica e extensão do IFTO. Anais Eletrônicos. JICE 2010.

COMPANHIA PAULISTA DE FORÇA E LUZ - CPFL ENERGIA. Arborização urbana viária: aspectos de planejamento, implantação e manejo. Campinas: CPFL Energia, 2008. 120 p.

DEL RIO, Vicente; OLIVEIRA, Lívia. Percepção ambiental: a experiência brasileira. 2. ed. São Paulo: Studio Nobel, 1999.

GOMES, M. A. S.; AMORIM, M. C. C. T.. 2003. Arborização e conforto térmico no espaço urbano: estudo de caso nas praças públicas de Presidente Prudente (SP). Caminhos de Geografia, Uberlândia, 7(10), p. 94-106.

GUZZO, P. Cadastro Municipal de Espaços Livres Urbanos de Ribeirão Preto (SP): Acesso Público, Índices e Base para Novos Instrumentos e Mecanismos de Gestão. Revista da Sociedade Brasileira de Arborização Urbana, v.1, n.1, 2006.

GUZZO, P. Estudos dos espaços livres de uso público e da cobertura vegetal em área urbana da cidade de Ribeirão Preto- SP. 1999. 106f. Dissertação (Mestrado em Geociências) Instituto de

Geociências e Ciências Exatas, Universidade Estadual Paulista, Rio Claro. 1999.

MAREK, C. F. Os impactos da arborização viária sobre a rede de distribuição 108 de energia elétrica: estudo de caso da Zona 7 de Maringá - PR. 2008. 89p. Dissertação (Mestrado em Engenharia Urbana). Universidade Estadual de Maringá. Maringá, 2008.

MASCARÓ, L. R. Ambiência Urbana. Porto Alegre: Ed. Sagra, 1996, 199p.

MELLO FILHO, L.E. de. Arborização urbana. In: ENCONTRO NACIONAL SOBRE ARBORIZAÇÃO URBANA, 1985, Porto Alegre. Anais. Porto Alegre: Secretaria Municipal do Meio Ambiente, 1985. p.51-56.

MILANO, M.S. Avaliação quali-quantitativa e manejo da arborização urbana: o exemplo de Maringá/ PR. Curitiba, 1988, 120 p. Tese (Doutorado em Engenharia Florestal) Setor de Ciências Agrárias, UFPR, Curitiba, 1988.

MALAVASI, U. C.; MALAVASI, M. M. Avaliação da arborização urbana pelos residentes - estudo de caso em Marechal Cândido Rondon, Paraná. Revista Ciência Florestal, v.11, n. 1, p. 189 -193, 2001

MIRANDA, T. O.; CARVALHO S. M. Levantamento quantitativo e qualitativo de indivíduos arbóreos presentes nas vias do bairro da ronda em Ponta Grossa - PR. Revista da Sociedade Brasileira de Arborização Urbana, Piracicaba, v.4, n.3, p.143-157, jul./set. 2009.

OLIVEIRA, A. F. de; PEREIRA, G. de A.; PEREIRA, J. A. A.; CASTRO, P. M.; COELHO, S. J. Produção 
e doação de mudas realizada pela companhia energética de minas Gerais (cemig) e a percepção de moradores quanto ao plantio destas em Áreas urbanas. Revista da Sociedade Brasileira de Arborização Urbana, v. 8, n.4, p. 47-58, 2013.

PREFEITURA MUNICIPAL DE SÃO PAULO. Manual técnico de arborização urbana. Ed. 2, 2005.

PREFEITURA MUNICIPAL DE PIRACICABA. Secretaria de defesa do meio ambiente. Manual de normas técnicas de arborização urbana. Piracicaba, 2007.

QUADROS, L. S.; FREI, F. Percepção ambiental dos residentes da cidade de Assis - SP com relação à arborização viária da Avenida Rui Barbosa. Revista da Sociedade Brasileira de Arborização Urbana. Piracicaba-SP, v.4, n.2, p.16-34, 2009.

RIO GRANDE ENERGIA. Manual de arborização e poda. 2000.

ROPPA, C; FALKENBERG, J.R.; STANGERLIN, D.M.; BRUN, F.G.K; BRUN, E.J.; LONGHI, S.J.1 Diagnóstico da percepção dos moradores sobre a arborização urbana na Vila Estação Colônia - Bairro Camobi, Santa Maria - RS. Revista da Sociedade Brasileira de Arborização Urbana, v. 2, n.2, p. 11-30, 2007.

SILVA, D. R. da. Diagnóstico da arborização das vias públicas do município de Ubá - MG. 2012. 51 f. Trabalho de Conclusão de Curso (Licenciatura em Ciências Biológicas) - Ciências Biológicas - Universidade do Estado de Minas Gerais (UEMG), Ubá, 2012.

SILVA, L. M. et al. Inventário da arborização em duas vias de Mariópolis/PR. Revista da Sociedade Brasileira de Arborização Urbana, v.3, n.1, p.36-53, 2008.

SILVA, L. F. Situação da arborização viária e proposta de espécies para os bairros Antônio Zanaga I e II, da cidade de Americana/SP. 2005. 80f. Dissertação (Mestrado em Agronomia) - Escola Superior de Agricultura Luiz de Queiroz, Piracicaba, 2005.

TEJAS, G. T.; SOUZA, R. M. S.; FRANCA, R. R.; NUNES, D. D. Estudo da variabilidade climática em Porto Velho/RO Brasil no período de 1982 a 2011. Revista de Geografia, v.29, n.2, p.63-82, 2012. 